\title{
Theory and Practice Divide in the Implementation of the Inclusive Education Policy: Reflections through Freire and Bronfenbrenner's Lenses
}

\author{
Dikeledi Mahlo \\ Department of Inclusive Education \\ University of South Africa \\ mahlofd@unisa.ac.za
}

\section{Doi:10.5901/mjss.2013.v4n13p163}

\begin{abstract}
Globally, Inclusive Education is on the agenda of many educational institutions. However, the implementation of Inclusive Education in schools will require not only accepting learners with different learning needs in mainstream classrooms, but also determining whether those learners are being provided with appropriate support. In this article, I shall argue that a social justice discourse in Inclusive Education policy and practice necessitates changing systems that perpetuate power, and exclusion. The focus of this article is on those educational environmental factors that maintain and perpetuate social and educational injustice. Drawing on Paulo Freire's critical pedagogy and the work of Bronfenbrenner, this article, among others, explores Inclusive Education in a South African context; investigates the trends and challenges in the implementation of Inclusive Education policy and argues that Inclusive Education be a policy imperative.
\end{abstract}

Keywords: Bronfenbrenner's theory, Inclusive Education, power, exclusion, intersectionality.

For us inclusive education is not an end in itself, but a means to an end. It is about contributing to the realisation of an inclusive society with a demand for a rights approach as a central component of policy-making. Thus the question is fundamentally about issues of human rights, equity, social justice and the struggle for a non-discriminatory society. These principles are at the heart of inclusive educational policy and practice (Armstrong \& Barton 2007:6).

\section{Introduction}

The citation above captures the importance given to Inclusive Education as an ideological state apparatus in today's changed teaching and learning environment. However, the implementation of Inclusive Education has dominated debates in education around the world and different opinions have evolved on how best to make schools (as sites of justice or injustice) more inclusive. The 1994 Salamanca Statement reaffirmed the international trend towards Inclusive Education under the slogan "Education for All", incorporating regular education with inclusive orientation as the most effective means for combating discriminatory attitudes, creating welcoming attitudes and building an inclusive society. If the majority of children are given an effective education, this will improve the efficiency and ultimately the costeffectiveness of the entire education system (UNESCO 1994). Within this context, we argue that a social justice discourse in Inclusive Education policy and practice necessitates changing systems that perpetuate power and exclusion. Quite often, disabled learners (as the oppressed) experience intersectional subordination. Hence, Inclusive Education should draw on the notion of intersectionality whereby the notion of disability is conceptualised in conjunction with issues of race, socioeconomic background and gender, thereby providing alternative analytical lenses by which to challenge reductionist and neoliberal discourses of Inclusive Education.

Giroux (2003:13) argues that interrogating how power works through dominant discourses and social relations, particularly as these influence young people who are marginalised economically, racially, and politically, provides opportunities for progressives to challenge dominant ideologies and regressive social policies - policies that undermine opportunities for connecting the struggles over education to the broader crisis of radical democracy and social and economic justice. In this article, I shall argue that understanding the intersections of systems of oppression and challenging the multiplicity of factors that disable certain groups of students entail critiquing dominant ideologies, educational policies and institutional arrangements that maintain and perpetuate social and educational injustice. For me, the notion of intersectionality is adequately reflected in the "lens" of Paulo Freire's critical pedagogy. Freire's pedagogy focuses on issues of marginalisation, power, justice and social transformation; and can mobilise new theorising concerning the complex nature of disability and the ways in which disabled students are socially and educationally 
positioned.

As Ainscow (2000) articulates, different views of inclusion exist and there is no single perspective within a single country or school. The former South African Minister of Education, Kader Asmal, emphasised the fact that the complexity of a fast-changing society means that the formal teaching system is expected to address issues which were not previously regarded as part of education (Values in Education Manifesto 2001), such as supporting learners who experience barriers to learning and development. As a policy which acknowledges that all children can learn and need support, Inclusive Education is also about changing attitudes, behaviour, teaching methods, curricular and environment to meet the needs of all learners, thus enabling education structures, systems and learning methodologies accordingly (South Africa 2001). As the Department of Education (South Africa 2000:28) puts it, the establishment of an Inclusive Education system in schools would require appropriate district as well as institution level support services, and will involve more than simply accepting learners with different learning needs in mainstream classrooms.

Against this backdrop, there is a divide between theory and practice - at present, learners' environmental factors continue to perpetuate social and educational injustice, and lack the substance of intersectionality. I argue that the success or failure of Inclusive Education policy depends on those processes, structures, conditions and other mechanisms that need to be in place to promote the development of inclusive practices within the South African education system. My aim in this article is to explore and reflect on the barriers to the implementation of Inclusive Education policy in the Gauteng province. There are a significant number of factors that influence the implementation of Inclusive Education policy, but this article focuses on learners' environmental factors that maintain and perpetuate social and educational injustice. Central to this article is the assumption that Inclusive Education should draw on the notion of intersectionality, whereby the notion of disability is conceptualised in conjunction with issues of race and socioeconomic background. Drawing on Paulo Freire's critical pedagogy and the work of Bronfenbrenner, this article: (1) explores Inclusive Education in the South African context; (2) reflects on Bronfenbrenner's theory and Inclusive Education policy; (3) investigates the trends and challenges in the implementation of Inclusive Education policy; and (4) argues Inclusive Education as a policy imperative.

\section{Inclusive Education in the South African Context}

It is not my intention to dwell on the pedantics of trying to define the concept "Inclusive Education", given that there is an extant valuable body of literature on this specific issue. It is my contention, though, that it is essential to have a shared understanding of what Inclusive Education entails. To that end I will briefly sketch some of shared understandings of the notion of Inclusive Education. The concept "Inclusive Education" is multidimensional, broadly perceived and has several definitions - it is very fluid in nature. On one hand, for some scholars (Engelbrecht (1999; Swart \& Pettipher 2001), Inclusive Education is as a proposed strategy for achieving a democratic and just society; these scholars regard inclusion as the development of an inclusive society where, in a democracy, all members participate to the fullest extent and make a worthwhile contribution. On the other hand, UNESCO (2001) defines Inclusive Education as concerned with removing all barriers to learning, and with the participation of all learners who are vulnerable to exclusion and marginalisation. It is a strategic approach designed to facilitate all children's learning success. It addresses common goals of decreasing and overcoming all exclusions from human rights to education, at least at elementary level, and enhancing access, participation and learning success in quality basic education that is available to all. Barton (1999: 58) explains that Inclusive Education is: not integration and not concerned with the assimilation or accommodation of discriminated groups or individuals within existing socio-economic conditions and relations. It is not about making people as "normal" as possible.... It is ultimately about transformation of a society and its institutional arrangements such as education (Barton 1999: 58).

Discourses on Inclusive Education are not a post-1994 phenomenon. Indeed, they date back to the apartheid era, although such discourses tended to be almost exclusively about previously disadvantaged communities. In keeping up with the trends in Inclusive Education globally, South Africa developed a legislative and policy framework in which inclusion functions are mentioned with particular emphasis in the Education White Paper Six: Special Needs Education (South Africa 2001). Inclusive Education is defined as a learning environment that promotes the full personal, academic and professional development of all learners, irrespective of race, class, gender, disability, religion, culture, sexual preference, learning styles and language (NCSNETINCES 1998). In the South Africa context, the term refers to the education policy based on the principles of inclusion, which acknowledges that all children can learn and need support. It is also about changing attitudes, behaviour, teaching methods, curricular and environment, enabling appropriate education structures, systems and learning methodologies (South Africa 2001). 
It is my contention that the successful implementation of Inclusive Education policy is critical in achieving a democratic and just society. For Le Roux (2004), Inclusive Education is about providing opportunities to ensure that all learners develop to their full potential, whilst acknowledging that they can learn and succeed within mainstream education but need support if they are to do this. Inclusion promotes equal participation and non-discrimination for all learners in the learning process (irrespective of their abilities) within a single education and training system and with a continuum of learning contexts and resources according to learners' needs (South Africa 2001). In the same vein, Wade (2000) argues that Inclusive Education should represent a shift from a continuum of educational placements to a continuum of educational services. In the South African context, the Education White Paper 6 (2001) indicates that inclusion is a form of support to all learners, teachers and the system as a whole, so that the full range of learning needs can be met.

Prior to these recent developments, the belief was that assistance to learners with barriers was so specialised that only individuals with special training were capable of providing such assistance. This led to such learners being taught in special schools by specially trained teachers. If they encountered difficulties in the mainstream, they would be referred to educational support services, where specially trained helpers had to assess and assist these learners. Thus, the task of the school was simply to identify the learner and refer him or her for assistance. In contrast, the paradigm shift brought about by Inclusive Education has advocated the devolution of assistance to base level for those learners who experience barriers to learning. The view is advocated that assistance be handled by the class and subject teachers themselves, thus giving both the responsibility for solving these learners' problems before further steps are taken.

Obviously, teachers who are responsible for teaching such learners should have the knowledge, skills and the right attitude to be able to teach and guide these learners to reach their highest potential. As Ladbrook (2009) observes, Learning Support Teachers (LSTs) are employed by selected districts in Gauteng to service schools in the district with support for teachers and learners. Learners identified as having barriers to learning are referred by the school to the LSTs for intervention. Naidu (2007) describes a support teacher as one providing support in an Inclusive Education setting for other classroom teachers and learners experiencing barriers to learning. The importance of LSTs in this process lies in the fact that they give assistance to teachers in areas in which they lack skills, attitudes and knowledge. Although this process is still in its infancy, some of the strategies identified by Vogel (2003) for the implementation of Inclusive Education in South Africa include the following: (1) providing a strengthened education support service which will provide support to teachers, hence the employment of learning support teachers; (2) in-service training for regular teachers so that they can cope with learners who experience barriers to learning; and (3) retraining and reorganising district support services in order to provide teachers, and not only learners, with the support they need. Given that they consist of experienced teachers with collaborative and facilitating skills, LSTs' tasks could include consulting and working with other teachers and staff, parents and various outside agencies to make sure that learners succeed (South Africa 2005). The role of LSTs is to address barriers by participating in the Institution Level Support Team (ILST) structure, providing continuous support to teachers, and building teacher capacity in strategies that will support learners.

With this background in mind, a theory and practice divide exists in the implementation of Inclusive Education policy. Given that educational contexts in South Africa are characterised by a diverse learner population in every classroom, it is our contention that the specific support strategies needed are the cornerstones for the success of Inclusive Education. There is currently an absence of specific support strategies in the policies directed to addressing the needs of LSTs in order to ensure successful implementation of Inclusive Education in South Africa (and with particular reference to Gauteng province). At present, the LSTs visit different schools on a rotational basis, and expect to find learners with a diverse range of differences (either extrinsic or intrinsic). Extrinsic barriers are those that reside not within the learners themselves, but in their circumstances (e.g. their environment, home, upbringing, teaching, poverty, HIVIAIDS, and socio-economic status). The inadequacy of the factors mentioned above influences the learners' development and learning and, ultimately, compounds any other barriers to learning. Intrinsic barriers are those barriers located within the learner: physical, sensory, physiological, learning and developmental mental or intellectual impairments, single or multiple. The learner who is not identified early on and given appropriate support will definitely experience barriers to learning. I contend that, as things stand, the LSTs are experiencing frustrations, difficulties and challenges in terms of resources, budget, recognition, powers, regulations, support and guidelines - all of which are making it extremely difficult for them to execute their duties. Furthermore, the system seems fragmented, with little evidence of clarity on LSTs' practices and no uniformity across the province on how the LSTs system functions. 


\section{Bronfenbrenner's Theory and Inclusive Education Policy}

Urie Bronfenbrenner, one of the world's leading scholars in the field of developmental psychology, is not unfamiliar with the discourses of Inclusive Education. He claims that there are five environmental factors that impact an individual's growth and development: the micro-system, the meso-system, the exo-system, the macro-system and the chronosystem. What is of particular note is that each system depends on the contextual nature of the person's life and offers an ever-growing diversity of options and sources of growth. Bronfenbrenner's ecosystemic theory, as a conceptual tool, is the most commonly used theory in Inclusive Education. According to Bronfenbrenner, an ecological systems model views the learner as existing within a complex ecological context that consists of numerous intrafamilial and extrafamilial systems that influence the learner's development. Thus, to ensure the success of Inclusive Educational programming, it is critical to integrate individual and contextual processes and to examine interrelations among these systems. An ecological systems view of Inclusive Education suggests that children with or without disabilities develop in a complex social world and that it is necessary to observe interactions at multilevel contexts and examine changes over time at all levels (Xu \& Filler 2008)

With this background in mind, there is a dialectical relationship between Bronfenbrenner and Inclusive Education. Of particular significance is the fact that Bronfenbrenner's theory qualifies to be used as a conceptual tool to understand issues around the policy of Inclusive Education. Hence, the current educational thinking underpinning Inclusive Education reflects a move away from a pathological, theoretical approach to one that values the understanding of learning difficulties. As Landsberg, Kruger and Nel (2005:9) remind us, the challenge of the education system is to understand the complexity of the influences, interactions and interrelationships between the individual learner and the multiple other systems connected to the learner. This study used the theory of ecological systems, which is based on the work of Bronfenbrenner (1979:21), who affirms a vision for Inclusive Education. Ecology of Human Development. This involves the scientific study of the progressive, mutual accommodation between an active, growing human being and the changing properties of the immediate settings in which the developing person lives, as this process is affected by relations between the settings, and by the larger context in which the settings are embedded.

In summary, the ecological perspective demonstrates how a micro-system, (e.g. the home), is interwoven with the meso-system (e.g. the school), and wider society, in determining the level of comfort and contentment human beings experience as they go about their life courses. The theory also explains the differences in the individual's knowledge, skills and abilities and the role of the support system in guiding and structuring the individual. The overlapping micro-, meso-, exo- and macro- systems all contribute to form the whole, a whole that the individual will perceive as positive or negative (Haihambo 2010). The system of education could be a representative of various micro-systems that form the meso-system in this study. For example: teachers, district, school environment, provincial departments, support, and resources - any and all of these might be significant in explaining the experiences, attitudes, frustrations and motivation for LSTs in the execution of their duties.

\section{Trends and Challenges in the Implementation of Inclusive Education Policy}

Creating an Inclusive Educational environment for diverse groups of learners is a complex and often daunting task. Traditionally, educational practices have reflected a "one size fits all" approach to both curriculum and strategy that ignores fundamental individual differences (Xu \& Filler 2008). With this in mind, this section outlines the trends and challenges in the implementation of Inclusive Education policy and draws on the narratives of a study in the Gauteng province. In doing so, I ground my theoretical discussion by illustrating, in brief, that: (1) matters pertaining to Inclusive Education policy, (2) parental support, and (3) role confusion all have a dialectical relationship.

\subsection{Matters pertaining to Inclusive Education policy}

When reflecting on the findings it was evident that, although LSTs are motivated and trained to support Foundation Phase teachers in the implementation of Inclusive Education, there are other factors which influence the actual implementation of Inclusive Education. As Donald, Lazarus and Lolwana (2009) point out, the macro-system involves dominant social and economic structures as well as certain values, beliefs and practices that influence all the other social systems. In the South African context, the macro-system can refer to the level at which policy decisions about education are made, this being the Department of Education. They provide the provinces with the guidelines required to implement a particular policy according to their needs. During the course of the study, purposefully sampled participants confirmed 
that there were no clear structures or guidelines at this level to regulate LSTs' practices: "We don't have a policy running our duties, what do we call this what do we call this, the thing that guides our working we don't have it at the moment, they are still drafting it."

In fact, South Africa has some very clearly written policies in place, but the practical implementation of these policies is problematic, as was seen clearly when the Department of Education employed LSTs without considering the rules and regulations required to govern their practices. As far as this LST member is concerned, there has been no proper planning in the implementation of an Inclusive Education policy:

\begin{abstract}
... definitely sure some of the things are good on paper but the implementation part of it, well like whereby they Inclusive Education should have those resources person therapists, of which we don't have in our schools, we should have a school nurse but there is only one local nurse from the local clinic, and who has to move around schools about 48 schools at a time, so there is never sufficient manpower with regard to that, and also the implementation part of it really, training for the teachers to implement it.
\end{abstract}

\title{
4.2 Parental support
}

For Bronfenbrenner (1979), the involvement of parents in their children's education is generally accepted as essential to effective learning. In the same vein, Stofile (2008) notes that the philosophy of Inclusive Education emphasises the importance of parental involvement in children's education. Given this, South Africa's Inclusive Education policy in South Africa is based on the flawed assumption that all learners have parents who can be involved in their children's education. What happens in the family can obviously influence how learners respond at school. Most LSTs experience a situation in which whatever happens in the family influences how a learner responds at school:

... some learners their parents are not there they are neglected, some of the learners they live alone, there are no parents, the parents have died, meaning its child headed families, they look after themselves they have no one to take care of them, other learners they come to school hungry, other learners come from families were their families are dysfunctional, there are lots of fights, other learners they don't have parents they stay with their step-parents, others are abused, others are being raped their social life is just terrible and that results in learners having problems in class, they can't even concentrate in class because they are busy thinking about what happened at home yesterday or last night.

In other words, the various systems in place are in continuous interaction with each other and this in itself can influence how the learner responds in class. If the learner is struggling with a number of serious social and emotional problems, he or she will certainly find learning difficult, thus resulting in a learner with learning difficulties and a learner who is developing more slowly than his or her peer group. Furthermore, it may well be difficult for the LST to assist with such problems if other stakeholders (e.g. the social worker and the police) are not working together.

\subsection{Role confusion}

Dyson (in Symeonidou 2002:150) points to the growing debate over the role of a support teacher in a new context of more inclusive practice, and the fact that there is inconsistency in this role, inconsistence that could lead to segregation rather than inclusion. LSTs experience frustration because they define their roles in terms of the medical model, and see themselves as specialists whose job it is to go to schools and solve the learners' problems by assessing them, "diagnosing" what is wrong, and then designing an individual education plan (the "cure"). However, doing this undermines the vision of inclusion as far as redressing past imbalances and eliminating past irregularities are concerned. The medical model leads to learners being identified and segregated from the class for the purposes of receiving individual attention. This is evident in this LST member's response:

"My role is to help Foundation Phase Teachers to identify these learners who are having problems may be help them to administrate assessment usually so after identifying these learners I help them to may be develop an individualized support programme for the learner".

Inclusion is about not separating learners from their peers, but about supporting them within the class. Regularly withdrawing the learner from the mainstream classroom may well cause additional problems and lead to this learner being isolated from his or her peers (Nolan \& Gersch in Symeonidou 2002:150). 


\section{Inclusive Education as a Policy Imperative}

In recent years, the subject of Inclusive Education has sparked numerous debates in and outside academia. Part of the reason for these debates is that educational systems reproduce and perpetuate social inequalities and contribute to policy flaws in Inclusive Education. This article is therefore based on Freire's framework - I regard this framework as a humanist and liberating praxis. The use of Freirean pedagogy among the oppressed sections of society as a subject of discourse and research appears to be gaining favour among Inclusive Education researchers, administrators and practitioners in both western and developing nations. Freire's (1999) pedagogy, as humanist and libertarian, has two distinct stages. First, the oppressed unveil the world of oppression and, via this praxis, commit themselves to its transformation. Secondly, once the reality of oppression has been transformed, this pedagogy ceases to belong to the oppressed and becomes the pedagogy of all people in the process of permanent liberation; more specifically, it becomes the pedagogy of formerly oppressed Inclusive Education learners. In both stages, it is always through action in reflection that the culture of domination is culturally confronted. As Freire (1999) observes, students, as they are increasingly confronted with problems relating to themselves in the world and with the world, will feel increasingly challenged and obliged to respond to these problems. Furthermore, because they apprehend these problems as interrelated to other problems within a total context, rather than as theoretical problems, their resulting comprehension tends to be increasingly critical and thus less alienated. Their response to the challenge evokes new challenges, followed by new understandings, and gradually the students come to regard themselves as committed (Freire 1999).

Following on from the above, it is worth noting that the post-apartheid South African Constitution emphasises respect for the rights of all, with particular emphasis on the recognition of diversity. We note that this calls for an inclusive approach to education in the sense that all learners, as the oppressed and the marginalised, are entitled to appropriate education in an inclusive and supportive learning environment. Given the high levels of social inequalities in South African society, implementing Inclusive Education is a challenging task. Within this context, the question "What are the implications of Inclusive Education on Education For All (EFA) policy ideals and Millennium Development Goals (MDGs?" becomes critical for thinking around MDGs and EFA policy issues and for the roll-out and implementation of South Africa's Inclusive Education policy.

Scholars (Armstrong \& Barton 2007; Kenworthy \& Whittaker 2000; Rioux 2002) have empirically documented that educational inclusion, as a social discourse, constitutes an international policy imperative that promotes the rights of disabled children to be educated alongside their peers in mainstream classrooms. Most importantly, even though Inclusive Education is a relatively recent policy phenomenon, it embodies ideas and arguments that have long been discussed and debated. Philosophically, Inclusive Education reflects values and principles and is concerned with challenging the ways in which educational systems reproduce and perpetuate social inequalities with regard to marginalised and excluded groups of students across a range of abilities, characteristics, developmental trajectories, and socioeconomic circumstances. For this reason, inclusion is inescapably linked with the principles of equality and social justice in both educational and social domains (Ainscow 1999; Artiles et al 2006; Lipsky \& Gartner 1996; Sapon-Shevin 2003).

Inclusive Education, as social construct, is a very complex enterprise which calls for the provision of equal opportunities for all learners, more specifically the oppressed. While some countries (developed) have made tremendous progress, others (including developing and underdeveloped), have gone backwards. As Stofile (2008) puts it, in theory this sounds simple but, in practice, Inclusive Education presents enormous challenges to those who have to implement it. Within this context, there is a strong link between Inclusive Education policy flaws and EFA policy and MDGs. As a subsystem of the open system, Inclusive Education policy is therefore crucial to the successful implementation of EFA policy ideals and MDGs. Notwithstanding the existence of certain pockets of excellence, Inclusive Education policy implementation remains a challenge in South African schools, specifically in schools located within disadvantaged communities. For example, in spite of laudable international policy rhetoric around Inclusive Education, disabled children are still significantly excluded, marginalised and stigmatised in ostensibly more inclusive schools. Policy, by its nature, is not value neutral, but is "a matter of authoritative allocation of values" (Ball 1990:2). Ball further argues that policies cannot be divorced from interests, from conflict and from domination or justice. Policies are contested, negotiated and fought over by different interest groups or policy communities. How one judges the implementation of outcomes is therefore subjective and depends on whose values are validated in policy (Stofile 2008). In addition, the failure of implementation failure, like the success of implementation, is a highly contested concept in itself. Its description depends on the intentions, expectations and values of those involved in policy implementation.

This article indicates that, although the Department of Education in Gauteng has employed LSTs in the 
implementation of Inclusive Education, more focus should be put on assuring that LSTs are provided with adequate support in terms of human and emotional resources. Since they are travelling on a daily basis to different schools, provision needs to be made for such regular travelling. Implementation is still in its early stages so provinces are still trying to find out what does and what does not work. My study indicates that, although the Gauteng Department of Education has a structured plan in place for implementation in the Foundation Phase, greater care should be taken in ensuring that LSTs' needs are catered for. To begin with, it seems necessary to elevate the post level of LSTs, given the efforts they put in to making sure that Inclusive Education policy is implemented. Districts should therefore revisit and redesign their strategies for supporting LSTs; they should also design guidelines to regulate the practices of LSTs and redefine their status. Finally, they should provide LSTs with clarity about exactly where they belong.

Lastly, there are still some factors that influence the implementation of Inclusive Education, such as policy issues at macro-level. Provincial departments have a responsibility to develop provincial policies, such as employing LSTs to assist in the implementation of Inclusive Education. They also provide districts with guidance about how to proceed with implementation, but at the school level there could be a number of policies related to requirements of the South African Schools Act that may not carry inclusive practices and values (e.g. admission and language policies). These policies, at school level, might hamper the implementation of a well-documented policy (e.g. White Paper No 6) on Inclusive Education. This article emphasises the fact that, if provided with necessary resources, LSTs could be a valuable resource in the implementation of Inclusive Education simply because they can reach places where the Inclusive Specialist cannot; a consideration of their needs is therefore important for the successful implementation of Inclusive Education. Notwithstanding the above challenges, it is our contention that Inclusive Education is not getting the attention it needs, but is still regarded as an "add-on" to the curriculum. As such, it will be difficult for any form of Inclusive Education policy to achieve its purpose. In this study, Learning Support Teachers continue to regard Inclusive Education as less important than other subjects, and this obviously has a negative impact on the implementation of Inclusive Education. In fact, if Inclusive Education were to be implemented effectively, the benefits would be significant, especially for those learners who are experiencing barriers to learning.

\section{Conclusion}

In this article, I discussed Inclusive Education policy and practice issues that perpetuate power and exclusion. While I acknowledge the existence of various pockets of Inclusive Education excellence in South Africa, I am particularly concerned about the extent to which real transformation has not been achieved. Given the glaring inequalities that continue to characterise South African society and the complexity of Inclusive Education, it is reasonable to deduce that the successful implementation of Inclusive Education policy will remain a Utopian dream. Facilitating and constraining factors, and the success or failure of Inclusive Education policy implementation, is a product of the interaction between and among agents such as policy, central policy making bodies, teachers, learners, parents (caregivers), context, local communities, Department of Education officials and various social partners (Stofile 2008).

\section{References}

Ainscow, M. 1999. Understanding the development of inclusive schools. London: Falmer.

Ainscow, M. 2000. The next step for special education. British Journal of Special Education 27(2):76-80.

Armstrong, F. \& Barton, L. 2007. Policy, experience and change and the challenge of Inclusive Education: the case of England, in Policy, experience and change: cross-cultural reflections on inclusive education, edited by L. Barton \& F. Armstrong. Dordrecht: Springer.

Artiles, A.J., Harris-Murri, N. \& Rostenberg, D. 2006. Inclusion as social justice: Critical notes on discourses, assumptions, and the road ahead. Theory into Practice 45(3): 260-268.

Ball, S.J. 1990. Politics and policy making in education: exploration in policy sociology. London: Routledge.

Barton, L. 1999. Market ideologies: Education and the challenge for inclusion, in Inclusive education: supporting inclusion in education systems, edited by H. Daniels \& P. Garner. London: Kogan: $54-62$.

Bronfenbrenner, U. 1979. Ecology of human development: experiments by nature and design. Cambridge: Harvard Press.

Donald, D., Lazarus, S. \& Lolwana, P. 2009. Educational psychology in context. $3^{\text {rd }}$. edition. Cape Town: Oxford University Press.

Dyson, A. 2001. Varieties of inclusion. Paper presented at the conference, Vi Jomadas Cientificas de Investigacion sobre Personas con Discapascidad, Salamanca, Spain, 17-19 March.

Engelbrecht, P. 1999. A theoretical framework for inclusive education, in Inclusive education in action in South Africa, edited by P. Engelbrecht, L. Green, S. Naicker \& L. Engelbrecht. Pretoria: Van Schaik: 3 - 12.

Giroux, H.A. 2003. Public pedagogy and the politics of resistance: notes on a critical theory of educational struggle. Educational 
Philosophy and Theory 35(1): 5-16.

Haihambo, C.K. 2010. Inclusive education: challenges of students with disabilities in institutions of higher education in Namibia. DEd thesis, University of South Africa, Pretoria.

Kenworthy, J. \& Whittaker, J. 2000. Anything to declare? The struggle for inclusive education and children's rights. Disability and Society 15(2): 219-231.

Ladbrook, M.W. 2009. Challenges experienced by educators in the implementation of inclusive education in primary schools in South Africa. MEd dissertation, University of South Africa, Pretoria.

Landsberg, E., Kruger, D. \& Nel, N. (eds). 2005. Addressing barriers to learning: a South African perspective. Pretoria: Van Schaik.

Le Roux, N. 2004. Inclusion. STEPPS Educational Services.

Lipsky, D. \& Gartner, A. 1996. Equity requires inclusion: the future for all students with disabilities, in Disability and the dilemmas of education and justice, edited by C. Christensen \& F. Rizvi. Buckingham, England: Open University Press: 145 - 155.

Naidu, S. 2007. The changing role of a remedial teacher to a support teacher: a case-study of a primary school in Pinetown. MEd dissertation, University of KwaZulu-Natal, Durban.

Freire, P. 1999. Pedagogy of the oppressed. New York: Continuum.

Rioux, M. 2002. Disability, citizenship and rights in a changing world, in Disability studies today, edited by C. Barnes, M. Oliver \& L. Barton. London: Polity.

Sapon-Shevin, M. 2003. Inclusion a matter of social justice. Educational Leadership, 61(2): 25-28.

South Africa. National Commission on Special Needs Education and Training (NCSNET) \& National Committee on Education Support Services (NCESS). 1997. Quality education for all: overcoming barriers to learning and development. Pretoria: Department of Education.

South Africa. Department of Education. 2000. Revised National Curriculum Statement for Grade R-9. Pretoria: Government Printers.

South Africa. Department of Education. 2001. Education White Paper 6: special needs education - building an inclusive education and training system. Pretoria: Government Printers.

South Africa. Department of Education. 2002. Assessment guidelines for inclusion. Pretoria: Government Printers.

South Africa. Department of Education. 2005. Draft National Strategy on screening, identification, assessment and support. Pretoria: Department of Education.

Stofile, S.Y. 2008. Factors affecting the implementation of inclusive education policy: A case study in one province in South Africa. Published PhD thesis, University of the Western Cape, South Africa.

Swart, E. \& Pettipher, R. 2001. Changing roles for principals and educators, in Promoting learner development preventing and working with barriers to learning, edited by P. Engelbrecht \& L. Green. Pretoria: Van Schaik: $30-44$.

Symeonidou, S. 2005. Reclaiming cultural insights in conceptualising and theorising disability and disability politics: a case study of the Cypriot disability movement. PhD Thesis, School of Education. University of Cambridge.

Symeonidou, S. 2002. The changing role of the support teacher and the case of Cyprus: the opportunity for a cooperative teaching approach. European Journal of Special Needs Education 17(2):149-159.

Symeonidou, S. 2002. A critical consideration of current values on the education of disabled children. International Journal of Inclusive Education 6(3): 217-229.

Wade, S.E. 2000. Preparing teachers for Inclusive Education: case pedagogies and curricula for teacher educators. Mahwah, NJ: Lawrence Erlbaum.

UNESCO. 1994. The Salamanca statement and framework for action on special needs education. Adopted by the World Conference on Special Needs Education: Access and Quality, Salamanca, Spain, 7-10 June, Paris.

UNESCO. 2001. Open file on Inclusive Education. Paris.

Vogel, W. 2003. Who is condoning whom? A mental health perspective on barriers to learning. Education Africa Forum (6):114-119.

$\mathrm{Xu}$, Y \& Filler, J. 2008. Facilitating family involvement and support for Inclusive Education. The School Community Journal 18(2): 53-72. 